In such cases a large proportion of superjacent weight was transmitted through enormously hypertrophied spinous processes. Examples of these several conditions are illustrated in the paper referred to. Neugebauer of Warsaw has written very largely upon the subject of spondylolisthesis. He regarded the deformity as a rare one, and was only able to find one specimen of it in the museums of England. It is difficult to understand this, since, as I have already stated, the condition is normal to the anatomy of many labourers. As he has paid such special attention to the subject I cannot do better than quote his views ${ }^{5}$ upon the causation of the displacement. "Drei Möglichkeiten sind heute angenommen, die zur Elongation prädisponiren : Mangel des knöchernen Zusammenhanges zwischen vorderer und hinterer Wirbelbogenhälfte (1) in Folge von Defect der fötalen knöchernen Verschmelzung zwischen dem hinteren und vorderen Knochenkern des Wirbelbogens (natürlich ein- oder beiderseits); (2) in Folge von Fractur an dieser Stelle (hypothetisch); (3) in Folge von Druckusur bei andauernder Ueberlastung." 6 For full clinical and pathological details I would refer to Neugebauer's elaborate work on spondylolisthesis.

In the case I have described I am inclined to ascribe the causation of the deformity to changes induced by work though it would not seem improbable that the blows she received on the lumbar spine diminished the security of the lumbo-sacral articulation and so facilitated the subsequent development of the deformity. Another point of interest is, I think, the complete absence of the deep reflexes of the knee and ankle, whilst sensation was but slightly impaired.

St. Thomas's-street, S.E.

\section{ADMINISTRATION OF OXYGEN AND HYPO- DERMIC INJECTIONS OF STRYCHNIA IN ACUTE LOBAR PNEUMONIA.}

\section{By FREDK. W. SAUNDERS, M.B., B.C. CANTAB. \&c.}

The patient, a woman aged thirty-three, came under my care on Jan 14th of the present year. The kistory given was as follows : Exposure to cold and wet whilst skating on Jan. 7th ; fresh exposure on the following day; catamenia commenced on the 9th and ceased on the 10th, on which day she had a shivering fit and took to her bed, passing a very restless and sleepless night. On the following day there was vomiting. There was a slight amount of :cough, but no expectoration. She remained in bed until the 14th, when I saw her at midday. She presented a very flushed face, the skin was dry and burning, and she complained of pain in the back, with headache. The temperature was found to be $103.6^{\circ}$, the pulse 140 and respiration 44 . On examination there were exaggerated breath sounds over both apices in front, the first sound of the heart being embarrassed, and the second sound greatly accentuated. Vocal fremitus was much increased over the left base, extending up to the spine of the scapula and towards the mid-axillary line on that side, over which area there were well-marked dulness, indistinct crepitant râles, bronchial breathing and bronchophony. The right lung was clear, the tongue was very coated, and the bowels were open on the previous day. At 7 P.M. the physical signs remained unaltered; the pain in the back was much less, there was no headache, the temperature wa $103.2^{\circ}$, the pulse 140 , and respiration 40 . There was a slight amount of cough with rusty expectoration. There was no herpes labialis. The urine was loaded with lithates of a high colour, but no albumen was present.

Jan. 15th. - The patient appeared better in the morning, having had some sleep; the temperature was $103^{\circ} 3^{\circ}$, the pulse 120 and much stronger, and respiration 40 . The first sound of the heart was clearer. There wasno expectoration and there was but little cough. She was taking nourishment very well. At 7 P.M. the physical signs were as before, with the addition of a pleuritic rub all over the affected area. Temperature $102 \cdot 8^{\circ}$;

5 St. Petersburger Medicinische Wochenschrift, Nos. 7 und 24, 1889 Congress russischer Aerzte zu St. Petersburg (rom. 3.-10. Januar, 1889) "Three possibilities are admitted to-day to predispose to elongation defect of the osseous connexion between the anterior and posterior halves of the vertebral arch (1) in consequence of defect of the foeta osseous union between the posterior and anterior osseous nucleus of the vertebral arch (of course on one side or on both); (2) in consequence of fracture at this point (hypothetically); (3) in consequence of erosion by continuous pressure." pulse 140; respiration 45. The lips were of a darker colour than formerly. At 9.30 P.M. I found the patient in a comatose condition, the lips being purple, the face and fingers deeply cyanosed, the pupils widely dilated and reacting very feebly to light, the conjunctival reflex abolished, the pulse 160 and running, and respiration 60 and chiefly diaphragmatic ; the first sound of the heart was inaudible; the second sound was laboured and greatly accentuated. She was given hypodermic injections of $\tau^{\frac{1}{\delta}} \mathrm{gr}$. of sulphate of strychnia and ten minims of brandy, which were followed by an immediate improvement in the heart sounds and pulse. At 10.30 P.M. the hypodermic injections were repeated, and half a pint of strong hot coffee with two ounces of brandy were injected into the rectum. At 11.30 P.M. the strychnia was again given. After each of the injections the improvement in the quality of the pulse was most marked, the cyanosis also being somewhat diminished. About this time I was able to obtain a cylinder of Brin's oxygen. The patient was made to inhale a fairly strong current of the gas through a glass tube inserted between the teeth and connected with the supply by means of an indiarubber tube. In half an hour the cyanosis was much less marked, the pulse was 130 and fairly strong, respiration 50, and the first sound of the heart was coming back.

16th. - At 1.30 A. M. she exhibited movements of the arms anc legs, and the conjunctival reflex was regained, the pupils reacting well to light, whilst the cyanosis continued to decrease. At 2 A.M. she became delirious, with the pulse 120 , the cyanosis almost gone, and respiration 35. Half an hour later she was quite conscious and able to take food. Subsequently the gas was given for fifteen minutes every hour until 1.30 P.M., when the temperature was $98.4^{\circ}$, the pulse 124 and respiration 30 . At 10 P.M. the temperature was $100^{\circ}$, the pulse 110 and respiration 30 , what expectoration there was being distinctly rusty.

17th.-At 10.30 A.M. her colour was greatly improved. The gas was given for ten minutes twice during the night. Temperature $101^{\circ}$; pulse 116 ; respiration 33 . On examination soft bronchial breathing was heard all over the affected area, with sharp crackling râles and no pleuritic rub. The right lung was clear. Dr. Gee kindly saw the case with me and encouraged me to persevere with the treatment ther being employed. At 5 P.M. the cyanosis was returning, with the pulse 122 and respiration 40 . Oxygen was given continuously for an hour and a half with very marked improvement in her condition.

18th. - A similar improvement resulted on administering the gas, the twitching of the alæ nasi and at the angles of the mouth, disappearing, together with the cyanosis. At 11 A.M. the heart suddenly began to fail, with the pulse about 180 ; the first sound of the heart was inaudible, ano the breathing was very short and quick; there was recession of the skin covering the sides of the trachea and neck, witl well-marked recession between the ribs. Oxygen was given continuously for four hours, together with (in all) three hypodermic injections of strychnia and brandy. At 3 P.M. the heart was beating regularly and well, the first sound being clear and distinct. Temperature $1004^{\circ}$; pulse 110 ; respiration 28. At 6 P.M. a fresh attack of heart failure took place, the recession being even more pronounced than before. A similar line of treatment gave equally satisfactory results, the temperature becoming normal at 11.30 P.M., with the pulse 112 and respiration 28 .

19th. - Examination of the affected lung revealed an im provement in its condition; the dulness was much diminished and there were loud gurgling râles all over the affected area. There was a good deal of cough, but very little expectoration. The general condition was very much improved, the temperature being normal, the pulse 108 , and respiration 25 , and sbe was taking nourishment very well. At 9 P.M. the patient became greatly excited, with muttering delirium, and she made attempts to get out of bed. At midnight the temperature was $101^{\circ}$, the pulse 150 and respiration 30

20th.-At 4.30 A.M. the patient was in a state of maniacal excitement. The head was very hot and dry, the conjunctiva. were suffused, the pupils were somewhat contracted, and the pulse was 180 and very small. The first sound of the heart was unrecognisable and respiration 28. There was ceaseless rocking of the head, but no strabismus. There was some evidence of left otitis media. It was almost impossible to come to any opinion as to the presence of optic neuritis, owing to the restless condition of the patient. Her hair was cut close to the scalp, an ice cap was applied, and drachm doses of bromide of potassium were injected into 
the rectum every four hours. In the afternoon Dr. Gee again kindly saw the case with me and confirmed the diagnosis of meningitis, holding out but little hope of ultimate recovery. Owing to the extreme cardiac debility he would not, however, recommend any other line of treatment. Towards the evening the condition of the patient became more alarming, the bromide of potassium having little or no effect. She complained somewhat of pressure over the parietal bones. There was ceaseless noisy delirium, the pulse being over 180 and running, the pupils widely dilated and equal, and respiration 30 .

21 st. - At 5 A.M. I decided to give a hypodermic injection of $\frac{1}{80}$ gr. of hyoseyamine. In half an hour she was almost comatose, with an extremely small pulse, respiration being unaffected. Epileptoid convulsions came on, lasting an hour, and at 7 A.M. she passed into a semi-conscious state and appeared at the point of death. She again rallied after a hypodermic injection of brandy and strychnia, and subsequently she was able to take food by the mouth for the first time for some hours. Her pulse was now 110 and the temperature was subnormal. During the day she was quite conscious and sensible, but in a very nervous condition. Towards evening the former symptoms of maniacal excitement again came on, with a fresh rise of temperature, which was $101^{\circ}$. Dr. Ferrier kindly saw her with me at 9.30 P.M., agreeing in the diagnosis of meningitis, but he thought that optic neuritis was not present. Counter-irritation was carried out behind the ears and on the scalp with croton oil liniment, and half a drachm of paraldehyde with ten grains of antipyrin were injected into the rectum. After an hour she became semi-comatose and cyanosed, with very rapid breathing and the pulse incountable. A hypodermic injection of fifteen minims of sulphuric ether caused a fresh rally.

22nd.-About 9 A. Mr. another epileptoid seizure took place, with external deviation of the left eye. At midday she partly regained consciousness and died at 12.20 P.M.

From the 18th I was unable to obtain a specimen of the arine, everything being passed under her.

South Kensington.

\section{COMPOUND COMMINUTED FRACTURE OF THE SKULL, WITH INJURY TO BRAIN ; RECOVERY.}

By W. C. D. PRENDERGast, M.D., M.Ch. R.U.I.

ON January 4th, 1889, I was summoned to see a young man aged eighteen years, a taker-off at the Ubberley Pit, near Hanley. Whilst working at the bottom of a dip he was struck, through an empty waggon hook slipping off, by a Loaded waggon weighing $18 \mathrm{cwt}$. The length of the coal dip was ten yards, with a fall of eighteen inches to the yard. He was conveyed home, where I first saw him at 7 A.M. He was completely unconscious and bleeding profusely. On examining him I found that the scalp from ear to ear had been lacerated and stripped back, a portion of the periosteum adhering. A part of the skull-cap, comprising a fragment of the frontal bone, together with that portion of the middle and upper third of both parietal bones, was fractured and detached from the surface of the brain, remaining attached behind by a strip of bone at the parietal eminence. A small portion of brain matter, with adherent pia mater, was also discovered in the wound. Both body and wound were grimy with finely pulverised coal dust. The wound was washed carefully with a carbolised solution. The bones were replaced over the brain, some small fragments of bone being removed; the scalp, with the torn periosteum, was brought together with about twenty sutures. On the left side, at the anterior superior angle of the parietal bone, a portion of the scalp was completely torn away, leaving no possible chance of reflecting the scalp over the fractured bone. Compresses of carbolised 3olution and a head bandage completed the dressings. There was continuous oozing from the torn vessels of the diploë, so much so that, owing to the difficulty of controlling this form of bleeding, death from hæmorrhage seemed likely to ensue. Some trouble was experienced in cleansing the wound, on account of the presence of the fine coal dust. I have invariably found, however, that its presence does not interfere materially with the union of wounds. Nearly all incised wounds of colliers inflicted whilst at work heal by first intention. A tattoo mark is left which distinguishes the collier from all other workmen.

On Jan. 5th there was a slight return to consciousness, as was evidenced by the ability to swallow a little soda-and-milk, which was ordered, together with small doses of brandy, to rally the patient from the shock and the persistent hæmorrhage. There was no vomiting. The pupils were slightly dilated, but were acting.

Jan. 6th.-The dressings were removed and the hæmorrhage had nearly ceased. There was slight delirium at night, vomiting being absent. The wound was dressed with carbolised oil and absorbent cotton wool.

7th.--Delirium at night was slight. Food was taken better and the bowels were evacuated. Temperature $99.2^{\circ}$; pulse 126.

8th. - Temperature $99 \cdot 4^{\circ}$; pulse 112 . He slept better and food was taken well.

9th. - A portion of the scalp wound had healed by first intention. Five sutures were removed.

11th. - Suppuration showed itself at one or two points.

12th. - The remaining sutures were removed, the appetite was better, and sleep was prolonged without delirium.

13th. - The major portion of the scalp wound had healed by first intention. In one or two places, however, the bone was exposed; these in the course of a few days were covered with soft velvet-like granulations. From the points mentioned under Jan. 11th there was a continuous oozing of pus, pointing to the presence of some decaying fragments of bone. The case after this was treated as one of necrosis with suppuration.

About the end of January pain was complained of. There were a rise in the temperature and some slight vomiting. The scalp was shaved on Feb. 14th and at one spot, where the pain was greatest, an incision was made down to the bone. Some matter issued, and on probing a loose but not detached piece of bone was felt. The incision was kept open.

March 26th. - I cut down on the detached bone and removed it. It was a fragment of the frontal bone.

April 2nd.-I removed the remaining loose fragments of the frontal bone.

25 th. - I cut down and removed a portion of the parietal bone, including both the internal and external table, measuring two inches and a half in length and one inch and a quarter in breadth.

May 8th. - Another fragment of the parietal bone was removed, corresponding to the left anterior superior angle, and comprising both the internal and external surfaces.

June 10th. - A large fragment of the parietal bone was removed, measuring two inches in length and three-quarters of an inch in breadth, the major portion being the external surface only.

July 2nd. - Some smaller fragments were removed.

27th. - A large fragment of the parietal bone was removed. This was the last operation. The whole wound, together with the incisions, healed continuously and no further suppuration was apparent. The patient began to go out, rapidly regained strength, and about the end of August was able to resume work. Since that time he has enjoyed excellent health. A few months ago a few spicula of bone were thrown out. At present the whole tract is healed and the patient regularly performs his arduous work as a miner. On stooping he complains of a slight sense of giddiness.

Remarks. - The above case illustrates remarkably the possibility of recovery after the most extensive injury to the head. In this case there was an extensive scalp wound, destruction of a portion of the scalp and extensive fracture, with exfoliation of a large surface of bone. One vital factor, however, was absent; there was no pressure on the brain from depression of the cranial bones. Another point worth noticing-although this may not be a typical case to illustrate it by-is that fine coal dust, instead of being a deterrent to the healing of wounds, appears to have the opposite effect. Hanley.

The Matithews Duncan Migmorial.-A meeting of the subscribers to this memorial will be held on Monday next, when the report of the committee will be presented. It appears that the sum of $£ 6319 s$. has already been received and has been invested, after certain necessary expenses bad been paid, in the names of three trustees. The first award of the gold medal and prizes will be made in June next. 